\begin{tabular}{|c|c|c|}
\hline \multirow{3}{*}{$\begin{array}{r}\text { Case Reports in } \\
\text { Gastroenterology }\end{array}$} & \multirow{2}{*}{\multicolumn{2}{|c|}{ Case Rep Gastroenterol 2015;9:120-125 }} \\
\hline & & \\
\hline & $\begin{array}{l}\text { DOI: } 10.1159 / 000382074 \\
\text { Publisnea onine: April 30, } 2015\end{array}$ & $\begin{array}{l}\text { ( ) } 2015 \text { S. Karger AG, Basel } \\
1662-0631 / 15 / 0091-0120 \$ 39.50 / 0 \\
\text { www.karger.com/crg }\end{array}$ \\
\hline & \multicolumn{2}{|c|}{$\begin{array}{l}\text { This is an Open Access article licensed under the terms of the Creative Commons } \\
\text { Attribution-NonCommercial 3.0 Unported license (CC BY-NC) (www.karger.com/OA } \\
\text { license), applicable to the online version of the article only. Distribution permitted for non- } \\
\text { commercial purposes only. }\end{array}$} \\
\hline
\end{tabular}

\title{
Early Squamous Cell Carcinoma of the Anal Canal Resected by Endoscopic Submucosal Dissection
}

\author{
Yuzuru Tamaru ${ }^{a}$ Shiro Oka ${ }^{a}$ Shinji Tanaka ${ }^{a}$ Yuki Ninomiya ${ }^{b}$ \\ Naoki Asayama ${ }^{b}$ Kenjiro Shigita $^{b}$ Soki Nishiyama $^{\mathrm{b}}$ Nana Hayashi ${ }^{\mathrm{b}}$ \\ Koji Arihiro ${ }^{c}$ Kazuaki Chayama ${ }^{b}$ \\ Departments of ${ }^{\mathrm{a}}$ Endoscopy, ${ }^{\mathrm{b}}$ Gastroenterology and Metabolism and ${ }^{\mathrm{c}}$ Anatomical \\ Pathology, Hiroshima University Hospital, Hiroshima, Japan
}

\section{Key Words}

Squamous cell carcinoma $\cdot$ Anal canal · Endoscopic submucosal dissection

\begin{abstract}
The standard treatment approach for squamous cell carcinoma (SCC) of the anal canal includes abdominoperineal resection and chemoradiotherapy. However, there are currently very few reports of early SCC of the anal canal resected by endoscopic submucosal dissection (ESD). We report 2 rare cases of SCC of the anal canal resected by ESD. In case 1, a 66-yearold woman underwent a colonoscopy due to blood in her stool, and an elevated lesion, $15 \mathrm{~mm}$ in size, was identified from the rectum to the dentate line of the anal canal on internal hemorrhoids. The lesion was diagnosed as an early SCC of the anal canal, and ESD was successfully performed. The histopathological diagnosis was SCC in situ. In case 2, a 71-year-old woman underwent a colonoscopy due to constipation, and an elevated lesion, $25 \mathrm{~mm}$ in size, was identified from the dentate line to the anal canal. The lesion was diagnosed as earlystage SCC of the anal canal, and ESD was successfully performed. The histopathological diagnosis was SCC in situ. No complications or recurrence after ESD occurred in either case.
\end{abstract}

(c) 2015 S. Karger AG, Basel

\section{Introduction}

Squamous cell carcinoma (SCC) of the anal canal is a relatively rare malignancy, accounting for only approximately $2 \%$ of all gastrointestinal carcinomas [1]. The 5-year survival of

\begin{tabular}{ll}
\hline KARGER 125/s & $\begin{array}{l}\text { Shiro Oka } \\
\text { Hiroshima University Hospital } \\
\text { 1-2-3 Kasumi Minami-ku } \\
\text { Hiroshima 734-8551 (Japan) } \\
\text { E-Mail oka4683@hiroshima-u.ac.jp }\end{array}$
\end{tabular}


Tamaru et al.: Early Squamous Cell Carcinoma of the Anal Canal Resected by Endoscopic Submucosal Dissection

patients with SCC of the anal canal has been reported as 58\%. There are some reports regarding the potential prognostic factors of this tumor [2]. Similar to other malignant tumors, disease progression has been demonstrated to represent one of the major adverse prognostic factors for SCC of the anal canal [3]. Previously, abdominoperineal resection was the most commonly used treatment procedure for this malignancy; however, SCC has a good sensitivity to chemoradiotherapy and, for this reason, it has become the standard treatment strategy for SCC of the anal canal $[4,5]$. On the other hand, there are currently very few reports of early SCC of the anal canal resected by endoscopic submucosal dissection (ESD). Herein, we present 2 rare cases of early SCC of the anal canal resected using this approach.

\section{Case Reports}

\section{Case 1}

A 66-year-old woman consulted our hospital complaining of blood in her stool. She consequently underwent a colonoscopy. A white, flat, elevated lesion, $15 \mathrm{~mm}$ in size, was identified from the rectum to the dentate line of the anal canal on internal hemorrhoids (fig. 1a). Magnifying endoscopy with narrow-band imaging (NBI) showed irregular vascular patterns (dilatation, tortuous running, caliber changes, and different shapes) (fig. 1b). A chromoendoscopy with indigo-carmine dye showed the edge of the lesion clearly; it revealed a lobulated, flat, and elevated lesion (fig. 1c). Next, the lesion was further confirmed using iodine staining (fig. 1d). Endoscopically, it was diagnosed as an early SCC of the anal canal (carcinoma in situ). Subsequently, ESD was performed en bloc without any complications (fig. 1e, f). The resected tumor comprised well-differentiated SCC. Both the vertical and horizontal cut ends of the tumor were negative. In the superficial layer, koilocytosis, a change of cytoplasms with vacuoles, was recognized (fig. 1g). An immunohistochemical evaluation showed strong expressions of p53, Ki-67, and p16, indicating that the patient was likely infected with the human papillomavirus (HPV) (fig. 1h-j). The histopathological diagnosis was SCC in situ without vessel invasion. At the latest follow-up (12 months after ESD), the patient was recurrence-free.

\section{Case 2}

A 71-year-old woman consulted our hospital complaining of constipation. She underwent a colonoscopy, and a white, papillary, flat, elevated lesion, $25 \mathrm{~mm}$ in size, was identified from the dentate line to the anal canal (fig. 2a). A magnifying endoscopy with NBI showed irregular vascular patterns (dilatation, tortuous running, caliber changes, and different shapes) (fig. 2b). Chromoendoscopy with indigo-carmine dye showed the edge of the lesion clearly and revealed a lobulated, elevated lesion. In addition, this lesion was clearly visible inside the dentate line (fig. 2c) and easily identified by chromoendoscopy with iodine staining (fig. 2d). Subsequently, ESD was performed without any complications. The lesion was resected en bloc with the entire circumference of the rectum lumen (fig. 2e, f); it was found to be composed of SCC. Both the vertical and horizontal cut ends of the tumor were negative. The histopathological diagnosis was SCC in situ without vessel invasion. In the superficial layer, koilocytosis was observed (fig. 2g). An immunohistochemical evaluation showed strong expressions of p53, Ki-67, and p16 (fig. 2h-j). At the latest follow-up (19 months after ESD), she showed no sign of recurrence. 
Tamaru et al.: Early Squamous Cell Carcinoma of the Anal Canal Resected by Endoscopic Submucosal Dissection

\section{Discussion}

SCC of the anal canal is a relatively rare malignancy. It is strongly associated with HPV infection, which is the causative agent in approximately $80-85 \%$ of all patients. Anal intercourse and a high lifetime number of sexual partners increase the risk of persistent HPV infection in both men and women, which in turn may eventually lead to malignancy [6]. Among more than 130 different HPV subtypes, HPV16 is the most prevalent in anal carcinoma and is present in up to $89 \%$ of all HPV-positive anal carcinoma patients [7-9]. Increased p16 expression is a well-established surrogate marker for tumors with transcriptional active HPV [10]. Moreover, a long-recognized pathognomonic feature of HPV infection is the appearance of halo or koilocytotic cells in the differentiated layers of the squamous epithelium. These koilocytes are squamous epithelial cells that contain an acentric, hyperchromatic nucleus that is displaced by a large perinuclear vacuole [11]. For detecting early SCC of the anal canal, the use of magnifying endoscopy with NBI and indigo-carmine dye spraying has been previously reported [3]. NBI is a novel noninvasive optical technique that uses reflected light to visualize the organ surface and it can be used to qualitatively diagnose and differentiate between neoplastic and nonneoplastic esophageal lesions [12]. Many studies have demonstrated the usefulness of NBI findings by discovering brownish dots [dilated intraepithelial papillary capillary loops (IPCLs)], tortuous IPCLs, caliber changes in IPCLs, a variety in IPCL shapes, demarcation lines, and brownish epithelium in the diagnosis of squamous mucosal high-grade neoplasia [12]. Similarly to esophageal neoplasia, SCC of the anal canal also consists of malignant squamous cells. Therefore, it is considered possible to qualitatively diagnose SCC of the anal canal using NBI. Colorectal ESD has become a standard therapy for large early colorectal carcinomas in Japan [13], largely owing to the fact that it can be used to resect most types of lesions, regardless of their size or location [14]. However, colorectal ESD is more technically demanding than esophageal and gastric ESD, as the anatomic features of the large intestine, which is a long luminal organ with many folds and flexures, hinder the manipulation of the endoscope for some lesions, and due to the fact that the intestinal wall is thin and easy to perforate. There have been some reports indicating that the establishment of a systematic training program for the technically more difficult colorectal ESD, in addition to the further development and refinement of ESD-related instruments, devices, equipment, and injection solutions, may help facilitate the increased use of colorectal ESD throughout the world $[14,15]$. We have previously reported on the clinical usefulness of ESD for lesions close to the dentate line, which should be performed with the following considerations in mind: (1) local anesthesia to prevent anal pain should be administered before submucosal injection of hyaluronic acid; (2) a shallow peripheral mucosal incision should be made to prevent bleeding, and (3) the blood vessels should be appropriately handled using hemostatic forceps [15]. As demonstrated in the present study, even in cases of anal canal tumors, we could perform ESD successfully using this procedure. In the future, as the clinicopathologic characteristics and prognosis of early SCC of the anal canal are currently not clear, further studies are needed in order to reveal the indications of ESD for early SCC of the anal canal.

\section{Disclosure Statement}

The authors declare that they have no conflicts of interest concerning this paper. 
Tamaru et al.: Early Squamous Cell Carcinoma of the Anal Canal Resected by Endoscopic Submucosal Dissection

\section{References}

1 Jemal A, Siegel R, Ward E, et al: Cancer statistics, 2007. CA Cancer J Clin 2007;57:43-66.

-2 Bilimoria KY, Bentrem DJ, Rock CE, et al: Outcomes and prognostic factors for squamous-cell carcinoma of the anal canal: analysis of patients from the National Cancer Data Base. Dis Colon Rectum 2009;52:624-631.

-3 Morisaki T, Isomoto H, Akazawa Y, et al: Beneficial use of magnifying endoscopy with narrow-band imaging for diagnosing a patient with squamous cell carcinoma of the anal canal. Dig Endosc 2012;24:42-45.

$\checkmark 4$ UKCCCR Anal Cancer Trial Working Party: Epidermoid anal cancer: results from the UKCCCR randomised trial of radiotherapy alone versus radiotherapy, 5-fluorouracil, and mitomycin. Lancet 1996;348:10491054.

-5 Ajani JA, Winter KA, Gunderson LL, et al: Fluorouracil, mitomycin, and radiotherapy vs fluorouracil, cisplatin, and radiotherapy for carcinoma of the anal canal: a randomized controlled trial. JAMA 2008;299: 1914-1921.

-6 Glynne-Jones R, Nilsson PJ, Aschele C, et al: Anal cancer: ESMO-ESSO-ESTRO clinical practice guideline for diagnosis, treatment and follow-up. Eur J Surg Oncol 2014;40:1165-1176.

7 Frisch M, Glimelius B, van den Brule AJ, et al: Sexually transmitted infection as a cause of anal cancer. N Engl J Med 1997;337:1350-1358.

-8 Abramowitz L, Jacquard AC, Jaroud F, et al: Human papillomavirus genotype distribution in anal cancer in France: the EDiTH V study. Int J Cancer 2011;129:433-439.

-9 Valmary-Degano S, Jacquin E, Prétet JL, et al: Signature patterns of human papillomavirus type 16 in invasive anal carcinoma. Hum Pathol 2013;44:992-1002.

$\checkmark 10$ Serup-Hansen E, Linnemann D, Skovrider-Ruminski W, et al: Human papillomavirus genotyping and p16 expression as prognostic factors for patients with American Joint Committee on Cancer Stages I to III carcinoma of the anal canal. J Clin Oncol 2014;32:1812-1817.

11 Krawczyk E, Suprynowicz FA, Liu X, et al: Koilocytosis: a cooperative interaction between the human papillomavirus E5 and E6 oncoproteins. Am J Pathol 2008;173:682-688.

$\checkmark 12$ Yoshida T, Inoue H, Usui S, et al: Narrow-band imaging system with magnifying endoscopy for superficial esophageal lesions. Gastrointest Endosc 2004;59:288-295.

13 Tanaka S, Oka S, Chayama K: Colorectal endoscopic submucosal dissection: present status and future perspective, including its differentiation from endoscopic mucosal resection. J Gastroenterol 2008;43: 641-651.

14 Tanaka S, Terasaki M, Kanao H, et al: Current status and future perspectives of endoscopic submucosal dissection for colorectal tumors. Dig Endosc 2012;24:73-79.

15 Nakadoi K, Tanaka S, Hayashi N, et al: Clinical outcomes of endoscopic submucosal dissection for rectal tumor close to the dentate line. Gastrointest Endosc 2012;76:444-450. 


\begin{tabular}{rl|l} 
Case Reports in & \multicolumn{2}{l}{ Case Rep Gastroenterol 2015;9:120-125 } \\
\cline { 2 - 3 } Gastroenterology & DOI: 10.1159/000382074 & $\begin{array}{l}\text { ○ 2015 S. Karger AG, Basel } \\
\text { www.karger.com/crg }\end{array}$ \\
\cline { 2 - 3 }
\end{tabular}

Tamaru et al.: Early Squamous Cell Carcinoma of the Anal Canal Resected by Endoscopic Submucosal Dissection
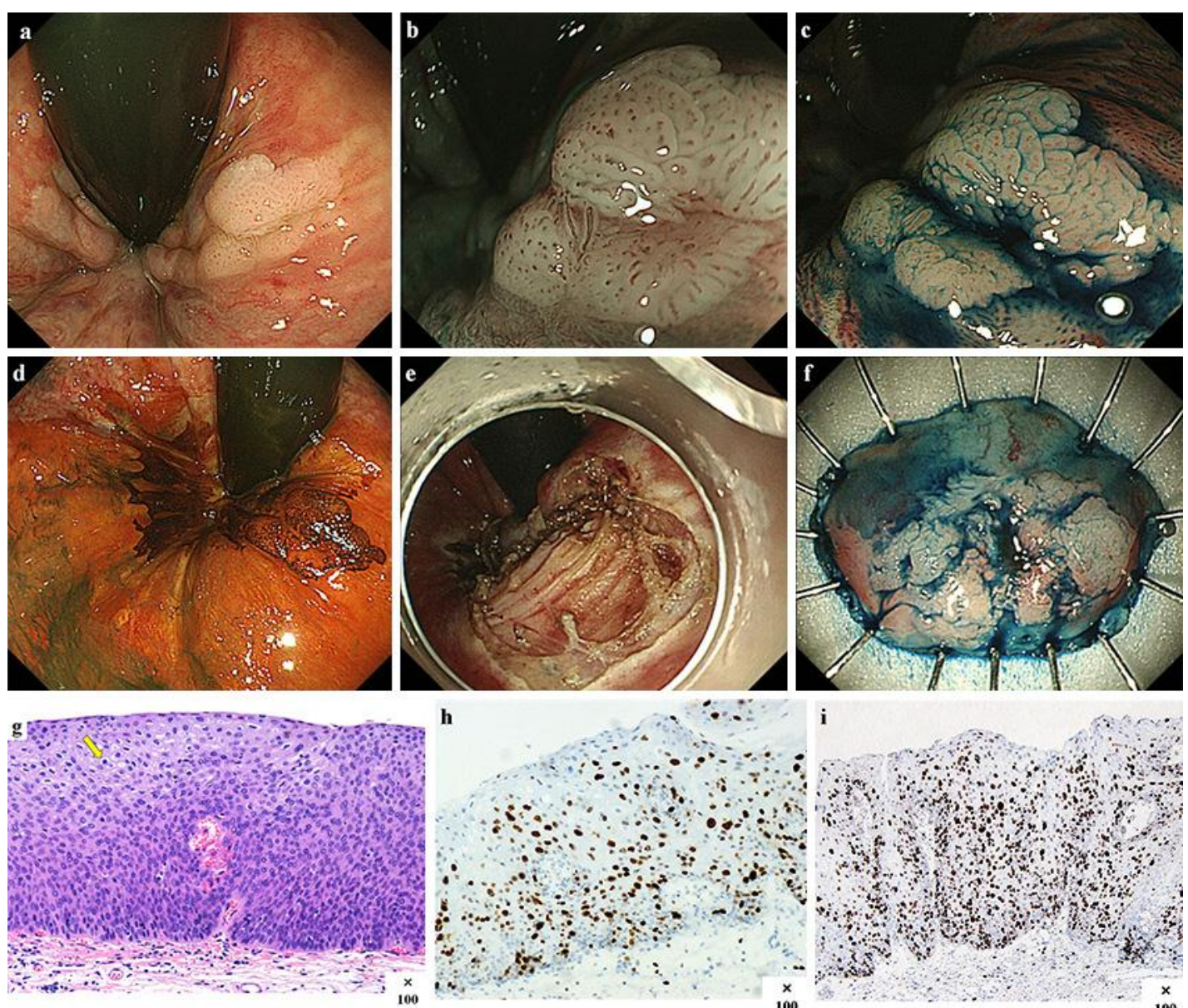

h
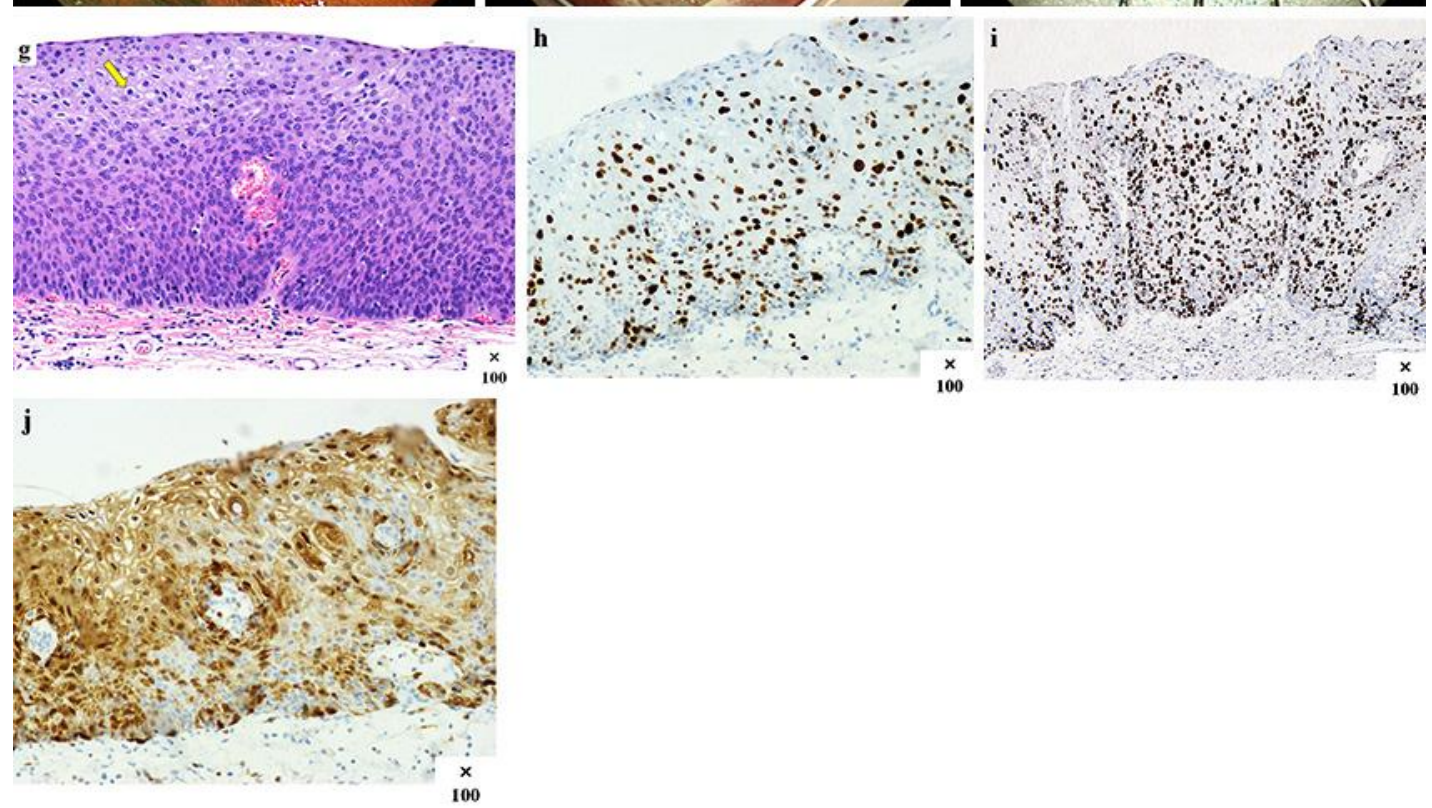

Fig. 1. a A white, flat, elevated lesion, $15 \mathrm{~mm}$ in size, was identified from the rectum to the dentate line of the anal canal on internal hemorrhoids. b NBI showed irregular vascular patterns (dilatation, tortuous running, caliber changes, and different shapes). c A chromoendoscopy with indigo-carmine dye showed the edge of the lesion clearly and revealed a lobulated, flat, elevated lesion. $\mathbf{d}$ The lesion was identified by chromoendoscopy with iodine staining as the stained area, with some unstained parts observed. e The ulcer after en bloc resection. $\mathbf{f}$ The resected specimen. $\mathbf{g}$ The tumor was composed of well-differentiated SCC in situ. The vertical and horizontal cut ends of the tumor were both negative. In the superficial layer, koilocytosis was recognized. $\mathbf{h}-\mathbf{j}$ An immunohistochemical evaluation showed strong expressions of p53 (h), Ki-67 (i), and p16 (j), indicating that the patient was infected with HPV. 


\begin{tabular}{|c|c|c|}
\hline \multirow{2}{*}{$\begin{array}{r}\text { Case Reports in } \\
\text { Gastroenterology }\end{array}$} & \multicolumn{2}{|c|}{ Case Rep Gastroenterol 2015;9:120-125 } \\
\hline & DOI: $10.1159 / 000382074$ & $\begin{array}{l}\text { (c) } 2015 \text { S. Karger AG, Base } \\
\text { www.karger.com/crg }\end{array}$ \\
\hline
\end{tabular}

Tamaru et al.: Early Squamous Cell Carcinoma of the Anal Canal Resected by Endoscopic Submucosal Dissection
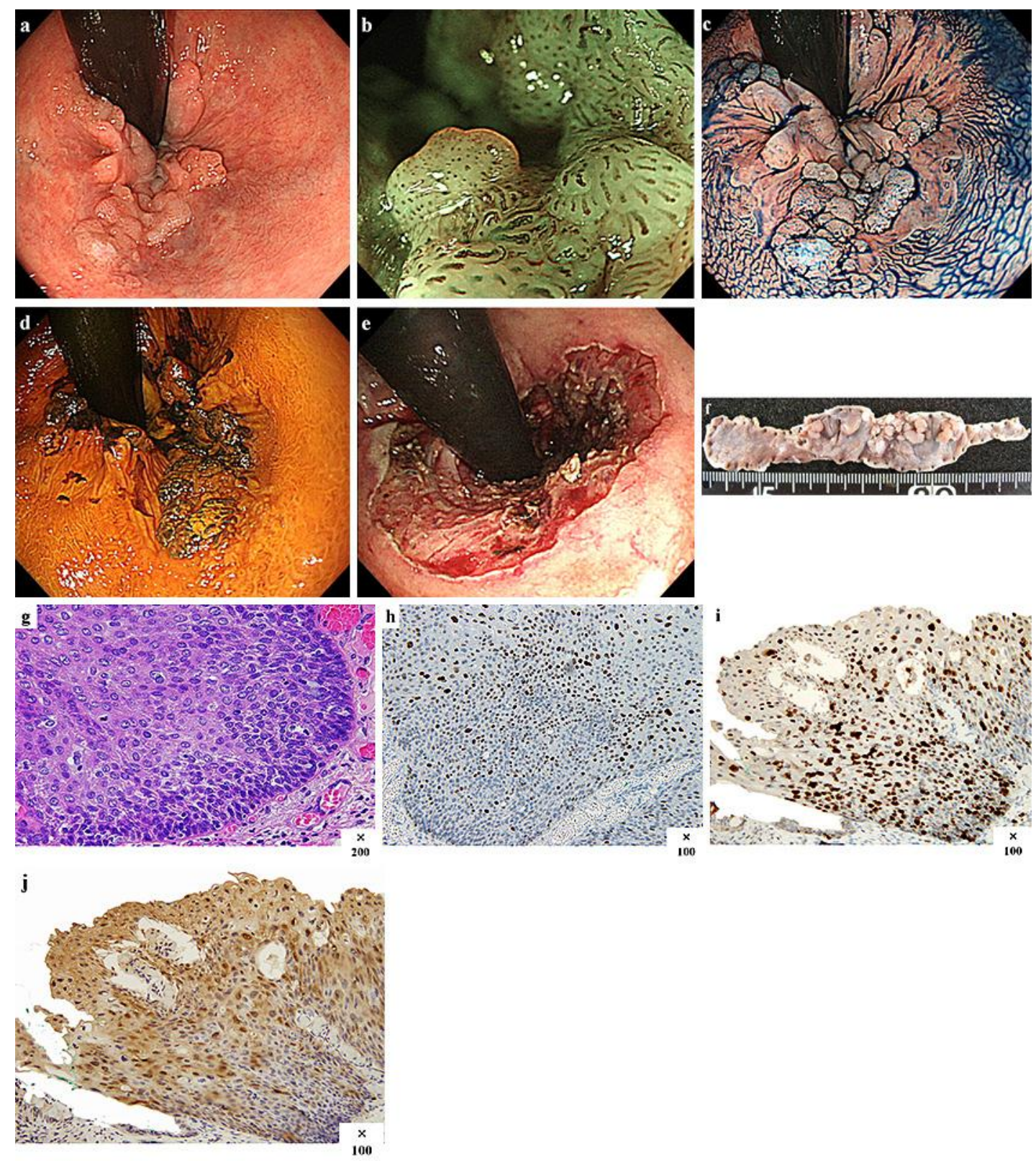

Fig. 2. a A white, papillary, flat, elevated lesion, $25 \mathrm{~mm}$ in size, was identified from the dentate line to the anal canal. b NBI showed irregular vascular patterns (dilatation, tortuous running, caliber changes, and different shapes) at the elevated lesion. c A chromoendoscopy with indigo-carmine dye showed the edge of the lesion clearly and revealed a lobulated, elevated lesion. In addition, this lesion was clearly visible inside the dentate line. $\mathbf{d}$ The lesion was identified by chromoendoscopy with iodine staining as the stained area. e The rectal area after en bloc resection showing the entire circumferential ulcer. $f$ Macroscopic findings from the resected specimen. $g$ The tumor was composed of SCC in situ. The vertical and horizontal cut ends of the tumor were both negative. The histopathological diagnosis was of SCC in situ without vessel invasion. $\mathbf{h}-\mathbf{j}$ An immunohistochemical evaluation showed strong expressions of p53 (h), Ki-67 (i), and p16 (j). 